\title{
LOS PROCESOS DE AUTORÍA EN LA CREACIÓN DE LIBROS EDUCATIVOS INTERCULTURALES: DEBATE Y REFLEXIÓN DESDE UN EJERCICIO DE RÉPLICA DE LA METODOLOGÍA DE «ENTRE VOCES»
}

\author{
Myriam Rebeca Pérez Daniel \\ rebeca.perez@unach.mx \\ Facultad de Ciencias Sociales \\ Universidad Autónoma de Chiapas \\ México
}

\section{RESUMEN}

La creciente oferta de libros educativos para la interculturalidad demuestra que el libro sigue siendo un instrumento didáctico y político. Por ello, cada vez se ha puesto mayor atención en sus procesos de producción, surgiendo una serie de principios implícitos en torno a cómo debería ser la autoría para garantizar la simetría entre los sujetos del escenario educativo y del espacio público. Este artículo pretende debatir y reflexionar en torno a ellos a partir de un ejercicio de réplica de una autoría horizontal denominada «Entre Voces», en un contexto de diversidad cultural distinto al que le dio origen. La conclusión apuntala hacia la consideración del co-análisis metacomunicativo entre los participantes como mecanismo indispensable para el logro de un texto educativo intercultural.

Palabras clave: libros de texto, procesos de autoría, comunicación intercultural. 


\section{ABSTRACT}

The increasing supply of educational books for interculturality is proof that books continue to be a didactic and political tool. Increasing attention has thus been placed on the production processes of this literature that has witnessed the emergence of a series of implicit principles around what authorship should be like in order to be able to ensure symmetry between subjects in the educational field and in public space. This paper aims to debate and reflect on these principles based on a replication exercise of horizontal authorship that has been called «Intra Voices» in a context of cultural diversity that is different from the context in which it originally emerged. The conclusion points to considering meta-communicative co-analysis among participants as an indispensable mechanism to achieve a text on intercultural education.

Key words: text books, authorship processes, intercultural communication. 


\section{ASPECTOS FUNDAMENTALES DE LA CREACIÓN Y ANÁLISIS DE TEXTOS EDUCATIVOS} INTERCULTURALES

Desde la oficialización del Modelo Educativo Intercultural Bilingüe, en el año 2001, como política de atención a los grupos indígenas del país, la producción de libros de texto interculturales ha ido creciendo exponencialmente. Esto deja en evidencia dos cosas: primero, que el libro de texto sigue siendo el instrumento por excelencia para manifestar una propuesta educativa, es decir, que sigue siendo el instrumento operativo del sistema escolar para aterrizar toda estrategia didáctica. Y segundo, el libro de texto oficial se ha erguido en México como un escaparate de gran relevancia para la visibilidad de los sujetos en el espacio público, o sea, es también un instrumento político (Martínez Bonafé 2002). Precisamente, por esa doble dimensión, es necesario poner particular interés en el proceso de producción de los textos educativos interculturales.

\section{EL CONTENIDO Y LA FORMA DE UN TEXTO EDUCATIVO}

En investigaciones previas (Pérez-Daniel 2008), he podido evidenciar cómo la forma del texto determina, en todo, su propuesta pedagógica y política. Incluso, lo determina más que su contenido. Usualmente, el contenido ha recibido mayor atención en el diseño de un texto educativo, a partir de la premisa de que su selección es, en sí, la propuesta educativa. Lo que deja claro el estudio es que el contenido no crea la propuesta, sino la forma en que se presenta.

La forma de un texto se determina, a su vez, por el proceso de autoría. Así, el sentido de un texto se crea a partir del paralelismo entre dos niveles: el nivel de la forma —intratextualy el nivel de autoría — extratextual—. El sentido se teje de afuera hacia adentro. Lo que pasa afuera determina lo de adentro. El nivel de la autoría, pues, se crea a partir de la relación entre el autor y su posible destinatario. El mecanismo que utilice para entablar un diálogo con él se refleja en la forma textual. La forma, a su vez, dicta el marco de interpretación del contenido. 
Barthes (2005) y Verón (1999) nombran el nivel de la forma como el nivel de la enunciación. El nivel de la enunciación funciona como una especie de escenario teatral en donde las formas del sentido se crean a partir de la aparición de ciertos sujetos y objetos, la relación que establecen entre sí y el posicionamiento de cada uno frente al otro, definiéndose a sí mismos y al sentido de su aparición. Es en este nivel en donde está encerrada la significación didáctica y política de un texto. Dicha significación no proviene de la aglomeración de sentidos contenidos en un entramado, sino en su orden. Así pues, en un libro de texto, la lección no se esconde en los contenidos elegidos, sino en la forma de plantearlos. Su contribución política no proviene de la visibilización de los sujetos que en él aparecen, sino en la forma en que son descritos o tratados a lo largo de ellos.

\section{LAS RELACIONES DISCURSIVAS ENTRE EMISOR Y RECEPTOR}

Barthes (2005) anticipa la constancia de la presencia de al menos tres elementos en un texto: el emisor-textual, el receptor-textual, y el objeto que los convoca. Emisor-textual y receptor-textual no son los sujetos de la realidad extratextual, sino sujetos discursivos que se forman a partir de su mención en el texto. Son, pues, una especie de personaje ficticio que se construye a partir de la forma en que se dicen las cosas. El objeto tampoco refiere a un elemento material, sino a un sentido que define la relación entre los dos sujetos.

En un texto educativo, emisor-textual y receptor-textual se traslapan con la imagen del docente y del alumno (Verón 1999). Entre ellos, en el escenario de la enunciación, es posible distinguir la propuesta que el texto hace sobre el tipo de relaciones pedagógicas que deben establecer entre sí o que deben establecer con otro tipo de elementos discursivos. Las relaciones pedagógicas, en todo caso, dice Verón (1999), pueden ser definidas en términos de simetría o complementariedad.

Un intercambio simétrico sería aquél en el que un acto comunicativo $\mathrm{X}$ realizado por $\mathrm{A}$ hacia $\mathrm{B}$, es respondido por $\mathrm{B}$ con un tipo de acto comunicativo del mismo tipo que $\mathrm{X}$. El debate es ejemplo de este tipo de relación. Un intercambio complementario, en cambio, es 
aquél en el que A dirige un acto comunicativo $\mathrm{X}$ a $\mathrm{B}$, pero $\mathrm{B}$ responde con un acto comunicativo cualitativamente distinto de $\mathrm{X}$ a $\mathrm{A}$. Un ejemplo de esto sería un diálogo basado en preguntas y respuestas.

Al fin, la simetría o la complementariedad de las relaciones entre sujetos y objetos enunciativos establecen entre ellos vínculos de poder, denuncia Verón (1999). Por eso explica:

En el intercambio simétrico, los protagonistas se autodefinen implícitamente como iguales, equivalentes o por lo menos comparables. En la interacción complementaria los actores se autodefinen como diferentes. Por eso, cuando se analizan intercambios complementarios es importante determinar, de los dos actores, quién se encuentra «arriba» (up) y quién se encuentra «abajo» (down) (p. 104).

Este tipo de relaciones fueron identificadas con claridad por Watzlawick, Beavin y Jackson (1997). Ellos, al estructurar su teoría de la comunicación humana, señalaban que ninguna de las dos formas puede considerarse como deseables o indeseables. Ambas tienen sus ventajas y sus limitaciones. Por ejemplo, el intercambio simétrico corre el riesgo de fomentar la competencia entre A y B, haciendo que cada vez sus respuestas tengan mayor intensidad o agresión, fomentando una escalada de ataques que hiera a los dos sujetos. El intercambio complementario, por otra parte, tiene el riesgo de volverse rígido, es decir, de hacer que el que domina la relación se acostumbre sólo a dominar, mientras que el sujeto receptivo se acostumbre a serlo siempre en todo intercambio. La pertinencia de un tipo de relación no la da la naturaleza misma de la relación, sino el contexto en el que aparece.

En un libro de texto educativo intercultural resulta relevante preguntarse por el tipo de relación que debe definir, a nivel enunciativo, la propuesta didáctica y política. ¿La simétrica o la complementaria? Hasta ahora, ha habido poco cuidado en responder esto. Acorde con la investigación realizada con anterioridad (Pérez Daniel 2008), la gran 
mayoría de la oferta textual intercultural plantea relaciones complementarias en el nivel enunciativo, fomentando el poder del docente sobre la vulnerabilidad del estudiante.

Así pues, pareciera que el propio discurso educativo tradicional, en donde el docente se posiciona por encima del alumno por su saber, determina, casi por lógica, una relación pedagógica complementaria presente también en los libros de texto. Dicha complementariedad se agudiza según el formato textual; los cuadernos de trabajo, por ejemplo, la enfatizan, puesto que parten de la diferencia entre el saber del estudiante y del docente para estructurar todo el contenido. Por ello, el primero no tendrá más remedio que ceñirse a lo estipulado por el segundo.

Los libros literarios parten del mismo supuesto, sólo que lo que se le presenta al niño no son cosas por hacer, sino historias por saber. Esta complementariedad en el libro de texto educativo, pues, es casi natural a partir del tipo de relaciones pedagógicas que se han naturalizado entre docentes y estudiantes en el aula mexicana. Sin embargo, su uso para la educación intercultural se convierte en delicado cuando se reconoce, además, en esa desigualdad u otra vinculada a la etnicidad. Esta otra desigualdad parte del proceso de autoría.

\section{EL DEBATE SOBRE EL PROCESO DE AUTORÍA PARA LOS TEXTOS EDUCATIVOS INTERCULTURALES}

En las instancias oficiales se reconocían, hasta el año 2006, dos procesos de autoría en la producción editorial para la interculturalidad que no procuraban la simetría; no por negarla, sino por desconocerla. En el primero, generalmente ligado a la producción de libros de corte literario, un autor en solitario compilaba y redactaba el texto, presentándolo para su publicación. En ocasiones, hacía alianza con un traductor para convertir la versión de su texto escrito en español a otro en alguna de las lenguas originarias del país. 
Este autor solitario, según el proceso reconocido, suele hacer la recopilación precisamente partiendo de su propio asombro ante una cultura que le es ajena. Por ello, la reconstrucción que ofrece es, al fin, desde una perspectiva externa. La desigualdad establecida parte, primero, de su calidad de intruso que reconstruye la versión de una cultura ajena y la presenta como si fuera propia a otros que la desconocen, o que sí la conocen por ser originarios de ella, pero no la ven con el mismo extrañamiento y fascinación que él. El intento, en todo caso, es el de aleccionar al destinatario sobre una realidad que el compilador domina y el receptor no.

El otro proceso de autoría frecuente está vinculado con grupos de expertos que, en equipo, diseñan estrategias didácticas para la enseñanza de un tema. En su calidad de especialistas, anticipan que todo destinatario está en desventaja sobre el conocimiento a tratar. Cuando ninguno de estos especialistas es miembro de la comunidad destinataria, la complementariedad entre emisor y receptor se vuelve también de tipo cultural. El emisor, entonces, no solo tiene el poder del saber, sino de pertenecer a una cultura dominante sobre otra caracterizada por desconocer. Estos grupos de especialistas, además, utilizan la traducción como un mecanismo para enfatizar esa desigualdad: se traduce lo que creen que pueda ser más difícil de aprender para el destinatario. El contenido, sin embargo, lo siguen definiendo ellos.

Ambos procesos de autoría asumen, por sí mismos, que el emisor tiene un saber especial que lo hace distinto y mejor que el destinatario. Cuando el emisor efectivamente no pertenece al mismo grupo identitario que el destinatario, esa complementariedad propuesta se duplica. No es, pues, que los libros de texto discriminen a partir de su proceso de autoría, sino que su proceso de autoría desigual se suma ya a una divergencia marcada entre emisor y receptor propia del formato educativo.

Es, pues, como si a la desigualdad existente entre un docente especializado frente a su neófito estudiante se le sumara el hecho de que el docente sea no indígena y se proponga 
educar bajo sus parámetros a un estudiante indígena. Eso es sumamente cotidiano en el panorama nacional, pero si se evalúa la situación desde el tipo de lectura que tiene eso en el espacio público, se asume que el estudiante indígena está naturalmente en desventaja frente a su docente no indígena. Incluso, simplificando, se asumiría, de igual forma, que el estudiante se encuentra en desventaja frente a su docente o que el indígena está en desventaja frente al no indígena.

Por este tipo de lecturas, recientemente ha habido una serie de reflexiones que plantean formas alternas de construir una autoría para la interculturalidad. Pareciera predominar, ahora, la idea de que un texto educativo para la interculturalidad debiera proponer una relación simétrica entre sus sujetos textuales, creando primero una relación simétrica entre los autores (ver UNEM 2007; Podestá 2007, como ejemplo). Con esto, se pretenden defender los principios educativos propuestos por CGEIB, ${ }^{1}$ en donde la visibilidad de la diversidad debe partir y buscar la igualdad y el respeto. Si la visibilidad de la diversidad no se hace a partir de un intercambio simétrico, aun en el nivel de la enunciación, la visibilidad tampoco será de tipo simétrica, por lo que la igualdad y el respeto aparecerán como ejercicios imperativos de un poder y no como cualidades naturales de la propia diversidad.

Así, en el campo educativo intercultural ha aparecido la inquietud por definir un procedimiento de autoría que garantice la simetría. En los foros de investigación, incluso, se apuntala ya una serie de principios que parecieran garantizar la autoría simétrica. Sintetizándolos, se concretarían en lo siguiente:

- La autoría debe ser grupal. La presencia de una sola voz fomenta la construcción de visiones parciales, por tanto, no fomenta la simetría didáctica y política entre los actores sociales en el espacio público.

- El grupo debe representar una voz. La validez del texto se la da el consenso grupal. Por tanto, la voz siempre habla en nombre de una comunidad de referencia. Si la voz habla sólo por sí misma, no fomenta la simetría. 
- El grupo debe iniciar, por sí mismo, el proceso de autoría. Incitar la construcción del texto, forzarla o proponerla, debilitaría la voz grupal. Por tanto, ya no reflejaría lo que el grupo quiere, sino lo que el interlocutor promueve, quebrando la simetría.

- El consenso garantiza la simetría. Contenidos y formas que sean validadas por la comunidad promueven, por sí mismas, las relaciones simétricas.

- La intervención de un ajeno sólo es válida si respeta el consenso grupal. De otra manera, rompe la simetría.

- La sola enunciación implica la aceptación de lo dicho. Algo enunciado no puede ser falso si tiene el consenso grupal. Esto garantiza la simetría.

- La simetría nace como cualidad del grupo, no como un posicionamiento frente al texto.

- La participación del grupo garantiza, por sí misma, su visibilidad en el espacio público de manera políticamente correcta.

- La visibilidad del grupo sólo se logra con la denuncia. Por tanto, la denuncia garantiza la simetría frente al lector.

- La visibilidad empodera por sí misma. Eso garantiza la simetría frente al lector.

- La visibilidad nacida del consenso del grupo garantiza la originalidad, la cual, a su vez, garantiza la simetría.

Estos principios son ejemplos del imaginario que se ha formado en torno a la autoría intercultural. Existen diversas perspectivas que inspiran la búsqueda de la horizontalidad en la autoría intercultural —educativas, sociológicas, antropológicas, políticas, etcétera-. Las que se han propuesto como objeto de reflexión en este artículo son las comunicativas.

\section{LA PROPUESTA DE UNA METODOLOGÍA DE AUTORÍA SIMÉTRICA: «ENTRE VOCES»}

En el afán, primero, de comprobar si existe realmente una serie de principios que puedan garantizar un tipo de intercambio didáctico y político de tipo simétrico en un texto educativo a nivel comunicativo, y segundo para probar si realmente el intercambio 
simétrico es el ideal para una educación intercultural, se hizo un ejercicio de autoría para un texto intercultural con un tipo de metodología que, en su primera aplicación, había buscado seguir estas directrices.

La metodología elegida fue la propuesta por Corona Berkin (2007) en el texto «Entre voces». Cabe aclarar que dicha metodología implica, precisamente, el análisis del proceso de autoría como mecanismo para darle sentido a los textos. Por ello, seguirla puede dar luz a lo que aquí se pretende responder. A continuación se expone parte de la historia de «Entre voces» para dilucidar, precisamente, los cuidados procedimentales que la definen como una metodología de autoría y de análisis.

En el año 2005, el Centro Educativo Tatutsi Maxakwxi, CETM, manifestó a la Dra. Sarah Corona la inquietud por crear un material educativo que cumpliera sus expectativas con respecto a lo siguiente:

- Que les permitiera a los alumnos ejercitar la lectura en su propia lengua y en español.

- Que contuviera temáticas de interés para ellos, en donde ellos mismos, su realidad y su pensamiento, se vieran reflejados y pudieran identificarse.

- Que las temáticas les permitieran, también, familiarizarse con la realidad mestiza «occidental» con la que, tarde o temprano, se encontrarían y que les exigiría conocer de sus reglas implícitas.

Así, la Dra. Corona, junto con los docentes de CETM, emprendieron un diálogo para diseñar un procedimiento de autoría que les permitiera garantizar que el texto resultante cubriera lo esperado, es decir, en donde la voz wixárika dialogara con la voz occidental, haciendo ver sus diferencias y confluencias; un texto, pues, que no solo permitiera a los jóvenes wixaritari reconocerse a sí mismos y a los «otros» de su realidad, sino que también fuera una oportunidad para los jóvenes mestizos occidentales de encontrarse a sí ante esos 
otros tan cercanos. Con ese diálogo que cimentó las bases de la propuesta nació, de hecho, la tónica de la metodología y la idea del proyecto editorial Entre Voces.

Para la gestación de dicho proyecto editorial, la Dra. Corona creó un seminario en donde participaron los maestros wixaritari de CETM y profesores con experiencia en investigación y docencia de la Universidad de Guadalajara y la Universidad Autónoma de Querétaro. La idea era reproducir, precisamente, el diálogo que la Dra. Corona había ya establecido con los docentes wixaritari. Por eso, el espíritu del seminario incitaba a la discusión sobre los temas a tratar en el libro y poder acordar, al fin, no solo criterios generales para la elaboración del mismo, sino en sí el texto y las dinámicas que se debían reflejar en él.

Dicha directriz exigió a los participantes en la autoría del texto; vivir el seminario como una experiencia objetiva y palpable de comunicación intercultural. El resultado, entonces, no solo fue el texto en sí, sino una serie de dinámicas de diálogo que impregnaron el diseño editorial y pedagógico del libro con referencias concretas a las complicaciones de la simetría e, incluso, a las inevitables complementariedades. Así, «Entre voces» (Corona, 2007) se convirtió en un texto de educación intercultural, bajo un formato enciclopédico, de corte informativo, que pretende, con su diseño, provocar la reflexión sobre la diversidad a partir de la misma visibilización de la diversidad. En el texto no hay interpelaciones directas al lector, sino solo una exposición del sujeto que reflexiona sobre sí frente a otro, logrando que la experiencia del diálogo se haga palpable a nivel de la enunciación.

Lo que metodológicamente determinó la riqueza educativa y política del proyecto Entre Voces fue precisamente la posibilidad del diálogo. El encuentro cara a cara entre autores que hablaban de una misma temática, desde distintas posiciones culturales, permitió que ellos hicieran una metarreflexión sobre lo que los constituía diferentes frente al otro, develando, al fin, las posturas que les eran negociables y las que no. Ese encuentro fue, 
entonces, crucial para la construcción de un diálogo de ida y vuelta inmediata, basado no solo en la exposición de posturas, sino también en su reflexión, discusión y resolución.

Esta compleja experiencia de diálogo no hubiera tenido tanta profundidad si no le hubiera exigido a sus participantes dedicación de tiempo completo en los tres días del seminario. La posibilidad de seguir dialogando, aun en espacios no formales, logró un efecto de choque y desacuerdo natural a partir de otras diferencias difíciles de convocar en espacios formales. El manejo del tiempo, los límites de lo privado y lo público, los protocolos de formalidad, los estatus de autoridad, incluso lo que es considerado como autoría; todo esto surgió como parapeto de posibles intenciones de limitar el intercambio a lo meramente cordial e indispensable. Precisamente los elementos de diferencia permitieron a los participantes caer en cuenta sobre los elementos que los definían frente al otro y que les resultaban indispensables exponer para facilitar la comprensión de sí. Sin esto, la comprensión no hubiera sido real.

Así, los textos resultantes no fueron, pues, un producto elaborado individualmente, bajo las propias suposiciones de lo que el otro requería saber, sino textos creados a partir del encuentro, de las interpelaciones, de las dudas, de las aclaraciones, de las precisiones y negociaciones frente al otro. Por ello, a nivel de la enunciación, no hay descripciones sobre el receptor, sino un trabajo del autor por definirse frente a él.

Se buscó la horizontalidad con siete mecanismos específicos:

1. La idea del texto no surgió a partir de la investigación en el campo de la comunicación, sino como petición de la comunidad que deseaba ser evidenciada.

2. Todos los participantes estaban en calidad de autores. No había funciones previamente establecidas, sino que se crearon en la propia interacción. 
3. Todos los autores tenían textos previos que fueron expuestos en el encuentro y que, a partir de su exposición, fueron modificados. Es decir, ningún autor tuvo tiempo de más o tiempo de menos que le diera una ventaja en el encuentro.

4. Tanto las modificaciones como el objetivo del encuentro, en sí mismo, dependían enteramente de la interacción, por lo que había un punto común de incertidumbre sobre el producto final. Nadie sabía qué iba a resultar de todo eso. Todos estaban, entonces, en igualdad de condiciones con respecto al producto final.

5. En la interacción misma se estableció que el texto que se creara partiera de la propia exposición, es decir, sobre lo que cada uno deseaba hacer visible sobre sí, no sobre la suposición de lo que los otros son o debieran saber. Esto permitió la horizontalidad entre emisores y receptores.

6. El texto al fin se conformó como una colección de diversas vistas sobre sí ante otro. No se sugirieron preguntas de reflexión ni ejercicios, sólo la propia colección de visiones presentada, editorialmente, unas frente a otras, en páginas contrapuestas, en español y en wixárika, simultáneamente. El objetivo, los términos y las limitantes de la reflexión se dejaron enteramente al lector.

7. En caso de no lograr la simetría en el diálogo entre los autores, se esclarecerían las condiciones que provocaron la complementariedad. Dicha complementariedad no se encubrió, sino que se evidenció en la introducción en qué momentos fue y de qué manera se presentó. Por tanto, el lector pudo ver el impacto de la dominación en el texto mismo, decidiendo qué hacer con eso.

\section{«ENTRE VOCES» FRENTE A OTRAS METODOLOGÍAS DE AUTORÍA INTERCULTURAL}

Como es posible ver, esta caracterización metodológica de autoría se desvía en ciertos puntos de la autoría intercultural. Por ejemplo, asume la simetría entre autores a partir del reto textual y no a partir del consenso. También, plantea la visibilidad como un reto didáctico y político que impacta en el diseño iconográfico del texto y que no refiere al otro, sino a uno mismo frente al otro. Así, la visibilidad es parte del objeto de diálogo. 
Sin embargo, lo más significativo es lo último: el reconocimiento de que la simetría no siempre se logra y que no debe ocultarse la complementariedad, sino hacerla evidente desde su contexto. Y para hacerla evidente, es necesario reconocer el sentido de la complementariedad a nivel didáctico y político, es decir, a nivel enunciativo. Lo complementario no demerita al texto si se esclarece su sentido. Lo que le da valía al texto es precisamente el tipo de relaciones creadas en el intercambio y su esclarecimiento, ya que conforman una gama de discursos que de otra manera, sin el diálogo, no se construirían.

La apuesta didáctica del texto es que ese tipo de discursos, por sí mismos, propician la reflexión y el aprendizaje sobre lo intercultural. Por ello, es posible definir la dinámica de Entre Voces como una metodología de autoría y de investigación para la comunicación intercultural, puesto que provocando la comunicación intercultural se definió un camino alterno de autoría.

El resultado, pues, se dio a dos niveles: en el primero, se hicieron evidentes una serie de relaciones de distintos tipos entre los sujetos que no necesariamente fueron horizontales y cuya naturaleza, más bien, dependió de una serie de elementos que rebasaba la intención del texto y se enclavaba en la centralidad política de las temáticas en el espacio común en construcción. En el segundo, se produjeron diez textos con distintos grados de dialogicidad que encerraron una experiencia de intercambio específica, y que al final hacía visible una forma de aparecer en el espacio público. Los textos no pretendían mostrar una verdad, sino una versión sobre sí. Una voz que se expresa a sí misma.

De esta manera se formó un texto de corte informativo. Los textos de corte informativo proponen, precisamente, una relación simétrica entre emisor y receptor. ¿Por qué? Porque en el texto informativo es el emisor el que construye una plataforma informativa que pone a disposición del destinatario para que éste defina su uso y función. De cualquier manera, la información puede prestarse para distorsiones, pues el autor presenta datos sobre las 
temáticas como si estos definieran de forma absoluta al objeto o como si nada más se pudiera decir sobre él. La cualidad finita del texto informativo lo hace limitado. Sin embargo, siempre está en el poder del destinatario el modo de hacer uso de esa información. En ese sentido, el destinatario se encuentra al mismo nivel que el emisor. No importa la pertenencia étnica del emisor ni la traducción del texto, pues ambos se convierten en datos que el usuario puede o no usar.

En esto consistió el proyecto editorial Entre Voces. En síntesis, las directrices metodológicas que propone son las siguientes:

- Los sujetos que se han de mostrar en el texto tienen que participar, con la misma función, en el proceso de autoría. Una forma de hacerlo es lograr que cada uno exponga, en igualdad de circunstancias, su perspectiva sobre sí y sobre la realidad que desea proponer.

- La traducción y la compilación no pueden estar al mismo nivel que la producción. Por tanto, no son comparables. Para garantizar la simetría de los autores, deben participar con la misma clase de acciones.

- Aun cuando los autores participen con el mismo tipo de acción, es posible que se establezcan entre sí relaciones complementarias. La única forma de convertir ese fenómeno en una propuesta educativa es evidenciar las condiciones que produjeron la relación resultante.

- Para librarse de la relación complementaria entre docentes autores y estudiantes destinatarios, es necesario partir de lo que se quiere visibilizar y no lo que se supone que el otro carece. El diseño pedagógico recae, entonces, en la reflexión sobre las implicaciones de esa visibilización.

- Los textos de tipo informativo logran una simetría existente entre emisor y receptor, pues el emisor tiene el poder de definir la finitud de su información, mientras que el receptor tiene el poder de decidir qué hacer con ello. Un texto informativo que, además, sugiera actividades reflexivas, podría ser el formato ideal de un texto educativo para la interculturalidad. 


\section{EJERCICIO DE REPRODUCCIÓN DE «ENTRE VOCES» EN OTRO CONTEXTO INTERCULTURAL}

Así, en la búsqueda por probar si la simetría es controlable y propia de lo intercultural, se emprendió una réplica del proyecto editorial Entre Voces en mayo de 2010, ahora con el objetivo de elaborar un libro de texto dirigido a jóvenes universitarios, escrito por jóvenes universitarios, que reflexionaran en conjunto sobre cómo construir un espacio común en la universidad en el que pudieran garantizar la visibilidad de todos sus miembros y su participación. $^{2}$

La peculiaridad buscada en el texto propuesto como producto final, fue que los jóvenes autores aportaran su visión sobre la diversidad en la Universidad ${ }^{3}$ como miembros de la misma y, a su vez, como miembros de una de las distintas comunidades culturales del estado de Chiapas, no para aleccionar a otros, sino para hacerse visibles ellos mismos. Se trató, pues, de crear un texto intercultural para jóvenes universitarios, escrito por jóvenes universitarios, ${ }^{4}$ a partir de la metodología de autoría y comunicación intercultural propuesta por Corona (2007) en el texto de Entre Voces.

Así pues, se elaboró un Seminario-Taller donde el diálogo entre los jóvenes para la creación del texto imprimiera en éste la intención educativa intercultural desde su misma práctica. Es decir, en el esfuerzo que hicieron los jóvenes por investigar, exponer, hacer comprensible, analizar, cuestionar, negociar y acordar su punto de vista en la elaboración conjunta del texto, se rescató en una metarreflexión el ejercicio mismo de diálogo que se hizo desde diversas culturas; esto con el propósito de ofrecer pistas de formación para la interculturalidad en el ámbito universitario, desde la vivencia misma de los jóvenes universitarios. 
El texto, entonces, habló sobre diversos temas que los mismos jóvenes vinculan a la «visibilidad»y a la «participación» universitaria, abordados desde el punto de vista, actual y en perspectiva de un futuro, de su comunidad de pertenencia — mestizo, tseltal, tsotsil, ch'ol y zoque), con el fin de hacer reflexionar a todo estudiante sobre la diversidad y la interculturalidad.

El resultado arrojó pistas suficientes para probar los límites de la simetría en la autoría intercultural. $^{5}$

\section{REFLEXIONES EN TORNO A LAS DIFICULTADES DE LA SIMETRÍA EN LA AUTORÍA INTERCULTURAL}

El principal reto de la reproducción metodológica del proyecto Entre Voces era el de cuidar el cumplimento de las siete condiciones de simetría para la autoría intercultural. Como se verá a continuación, las complicaciones de seguirlas evidenciaron que tales condiciones no son las que producen un texto para la educación intercultural, sino la reflexión sobre los fenómenos comunicativos que se esconden detrás de ellas. Dichos fenómenos y reflexiones se podrían resumir en los siguientes tres:

1. Acerca de quién inicia el diálogo y qué tipo de relaciones se producen en el encuentro. Dentro de las propuestas de autoría alternativas, pareciera que la horizontalidad se asegura cuando el que inicia el diálogo es la comunidad receptora y no el investigador. De esta manera se pretende garantizar que la legitimidad del texto se la da la comunidad y no el campo científico.

Sin embargo, Watzlawick, Beavin y Jackson (1997) señalan, desde su teoría de la comunicación humana, que la legitimidad de un intercambio simétrico, en realidad, inicia con la intención de cualquiera de los dos elementos. Es decir, que lo legitima la igualdad no es que la inicie x sujeto, sino que la inicie cualquiera que asume al otro como su igual. 
En el caso Entre Voces, la comunidad wixaritari no solo inició el diálogo, sino que además escogió como su igual a la Dra. Corona; no así con todos los demás autores. A algunos autores los asumieron como ayudantes de sus tareas, a otros como sujetos que se imponían con el trato a la temática. Con algunos más, no les interesó siquiera dialogar, no por la persona en sí, sino porque no encontraban eco propio en lo que ellas decían. Por ello, surgieron también intercambios complementarios, dominados a veces por ellos, otras por los investigadores, pero desiguales al fin.

Lo que, al fin, evidenció el trabajo metodológico de Entre Voces es que la simetría es difícil de lograr, menos aun cuando se confía su logro a solo el origen del intercambio. El dejar que la comunidad inicie el diálogo no garantiza la igualdad. Hay, de hecho, una serie de elementos que condicionan las interrelaciones igualitarias entre sujetos. Watzlawick, Beavin, Jackson (1997) anteponen, por ejemplo, el sistema de intercambios del que vienen los interlocutores.

En un diálogo intercultural, dichos sistemas tienen que ver, ciertamente, con el ámbito cultural, pero no exclusivamente. Tienen que ver, también, con el historial personal de intercambios de cada sujeto. Dicho historial establece un marco de tendencias de interrelación que sirve como referencia a nuevas interrelaciones. Así, los sujetos tenderán a establecer el intercambio que suelen establecer en situaciones semejantes. Si alguien reacciona de manera complementaria, no es por el origen del diálogo, sino por el contexto que lo enmarca y los antecedentes de intercambio de los sujetos en contextos similares.

Watzlawick, Beavin y Jackson (1997) agravan, incluso, las dificultades de lograr un intercambio simétrico. Aun fomentando experiencias de intercambios simétricos y asociándolas con ciertos contextos, como el aula, aun así queda un resquicio de posibilidades que podría romper la simetría a partir de la voluntad del sujeto: uno de los interlocutores puede no aceptar el diálogo o desviar el intercambio propuesto por el otro a otro tipo de intercambios. 
Así, para asegurar un verdadero intercambio simétrico, sería necesario asegurar que todos los participantes en el encuentro estén dispuestos a asumir a los otros como sus iguales, aceptar su comunicación y hacerlo efectivo a partir de las experiencias previas de intercambios simétricos exitosos en el pasado. Todo esto se vuelve muy complejo, más aún si en el proceso intervienen sujetos cuyo diálogo se estipula, precisamente, por provenir de sitios distintos de un sistema desigual. Dicha desigualdad no surge de los sujetos, sino del sistema de interacción de referencia. Por tanto, la desigualdad no es natural, sino discursiva. No contemplar eso promueve la reproducción de los intercambios complementarios, aun cuando se cuide quién inicie el intercambio.

En el ejercicio de autoría con los estudiantes, esa búsqueda por la simetría resultó de lo más complicado. Primero, porque los estudiantes no manifestaron ningún interés por un intercambio con nosotros, en parte porque la diversidad visible en el espacio universitario no tiene que ver con la pertenencia cultural, ni siquiera con los derechos de visibilidad como estudiantes. Su preocupación manifiesta tiene que ver, precisamente, con el tipo de relaciones que establecen con los docentes y, como éstos, en la tradición pedagógica universitaria, fomentan una relación de tipo complementario, no buscaron iniciar el diálogo, sino responder a él.

Como los principios de la comunicación estipulan que un intercambio puede surgir de cualquier interlocutor y era nuestro el interés por generar uno con los estudiantes, fuimos los docentes quienes convocamos al encuentro. Sin embargo, como era de esperarse, el diálogo hacia la gran mayoría de nosotros fue de corte complementario. Sólo entre ellos y entre los colegas que decidieron entrar a sus reglas de convivencia fue cuando el diálogo se prestó para la simetría, pero no en todos los casos.

Algunos estudiantes decidieron, precisamente, no ver como iguales a sus compañeros. Estos casos resultan oportunos de análisis. Primero, porque el tipo de intercambio que los 
estudiantes que promovieron el diálogo complementario, en este ejemplo pertenecientes a una comunidad étnica, esperaban de sus compañeros un énfasis en la pertenencia comunitaria. Esperaban esto porque, acorde con sus experiencias, todas ellas vinculadas con «encuentros interculturales» en donde el centro del diálogo se hacía a partir de su lugar de origen, esto era lo que se hacía. Por tanto, asumieron que esos referentes eran, precisamente, los que los definían frente a los otros. Como los otros compañeros, auto nombrados no-indígenas, tampoco encontraban referentes concretos de su comunidad — la gran mayoría era migrante-, se posicionaron en desventaja ante ellos.

En esa desventaja, se inició un intercambio desigual: «enséñenos sobre su comunidad». En el intercambio, la diferencia enfatizada estuvo en la posesión o no de una comunidad de referencia. Así, el diálogo establecido se dio entre los que tenían una comunidad de referencia y los que carecían de ella. Nótese que el intercambio no enfatizó en las culturas, sino en la pertenencia a una comunidad que, luego, se tradujo en condiciones y necesidades específicas como estudiantes. A los que tenían una comunidad les limitaba la distancia, la lengua, el compromiso con los suyos, los pocos recursos, etcétera. A los que no tenían una comunidad les limitaba la falta de referentes que les motivaran.

Al final, pues, esa diferencia marcó un posicionamiento frente a lo escolar y no frente a la diversidad cultural. En todo caso, los estudiantes que sí poseían una comunidad se encontraron frente al dilema de si aceptar o no ese intercambio. Unos aceptaron y trataron de enseñarles a los demás las características de su comunidad, además de lo difícil que les había sido entrar a la Universidad. Otros no aceptaron ese intercambio, pues les parecía que no iban a recibir nada a cambio. Así, la búsqueda de la simetría en un diálogo no dependió de quién lo iniciaba, sino de cómo se configuraba a partir de los sistemas que envolvían las relaciones de los sujetos. Incluso, el objeto del diálogo dependió de esos sistemas que envuelven a los sujetos. Como lo escolar imperó sobre lo cultural, la traducción de la pertenencia comunitaria decantó hacia las diferencias en las necesidades de los estudiantes. 
En todo caso, para que un texto sea intercultural no puede buscar la simetría de entrada, pero sí puede evidenciar cualquier tipo de relación establecida una vez que se den las condiciones de intercambio. Eso fue lo que se propuso Entre Voces. La evidencia de la naturaleza de los intercambios denuncia las condiciones del diálogo y su propia naturaleza. Forzar o simular una igualdad podría resultar engañoso, sobre todo en el ámbito de la enunciación. Evidenciarlas, puede resultar educativo por sí mismo.

2. La posición horizontal frente a la autoría y la creación de los textos. El retar a todos a una misma tarea forzó un tipo de «igualdad de condiciones» entre los autores. Dicha condición implicó la incertidumbre frente a lo que iba a resultar. Sin embargo, pese a que estuvieron en las mismas condiciones de incertidumbre, lo que se escapa de dicha búsqueda de la horizontalidad es lo que cada sujeto planea como objetivo didáctico para su propio texto, para su propia exposición.

Cuando todos los autores son docentes, como en el caso de Entre Voces, coinciden, al menos, en que sus interlocutores serán los estudiantes; aunque unos piensan en sus propios estudiantes y otros piensan en los estudiantes del otro. Cuando los autores son estudiantes, la diversidad de posibles destinatarios se hace menos obvia.

En la experiencia de reproducción realizada en UNACH, algunos estudiantes escogieron a otros estudiantes como sus destinatarios, unos pertenecientes a sus propios contextos, otros pertenecientes a diferentes. Sin embargo, la gran mayoría optó por asumir a los docentes como sus destinatarios: aquellos docentes que no perciben la diversidad de necesidades entre ellos. Así, el tipo de exposición que hicieron sobre sí no fue a partir de cómo querían ser vistos en el espacio común universitario, sino qué necesidades querían que vieran los docentes de su Universidad.

Las autorías interculturales suponen que esa visibilidad de sus necesidades los empodera frente al otro, en este caso, frente al docente. En el caso de Entre Voces fue distinto. No 
porque no resultara en un posicionamiento ventajoso frente a los otros, sino porque, en realidad, no buscaban ningún tipo de posicionamiento, sino solo un intercambio de visiones. Por tanto, una de las condiciones que hace evidente la metodología de Entre Voces es que el empoderamiento no es condición para la validación de los textos, sino el respeto del motivo que buscan sus autores para hacerse visibles.

En el caso de los textos universitarios, incluso, resultaron contrarios a un empoderamiento por parte del estudiante, puesto que decidieron centrarse en la visibilidad de sus necesidades y no de sus fortalezas. Es decir, optaron por debilitarse frente al poder del docente. Eso no le quita legitimidad al texto. Al contrario, legitima la igualdad de condiciones que permite que el resultado no se puede controlar, sino a partir de la propia interacción. De nuevo, lo que sugiere la metodología de Entre Voces en estos casos, es evidenciar el tipo de destinatario que cada autor asume y, por tanto, el origen de su propio mensaje. Lo que resulta educativo, entonces, en este caso es entender por qué el estudiante quiere ser reconocido por sus necesidades y no por sus cualidades. Eso dice mucho del sistema educativo universitario.

3. Las implicaciones de la visibilidad. Cuando los wixaritari iniciaron el diálogo de la autoría, tenían claro lo que querían decir sobre sí para sus propios hijos y para los hijos de los citadinos, puesto que se habían preguntado sobre ello en los años de docencia que precedieron el ejercicio de Entre Voces. Ante la pregunta de ¿qué quieres decir tú sobre ti a los demás?, alguien que no se haya enfrentado a la necesidad de visibilizarse, le puede resultar sumamente complicada de responder.

$\mathrm{Y}$ es que, en realidad, la visibilidad resulta muy retadora, pues de dicha visibilización depende la reacción que tengan los demás sobre nosotros. Discursivamente, cuando se trata de visibilizar algo, se suele optar por el uso de lugares comunes cuya respuesta está ya cifrada en un tipo de reacción concreta. Es decir, los lugares comunes se utilizan porque son modos de enunciarse ya probados en el espacio común. Al conocer ya sus 
consecuencias, es fácil predecir lo que podemos esperar de los demás al utilizarlos. Pocos optan por una visibilización no explorada.

En el ejercicio con jóvenes universitarios, el uso de dichos lugares comunes fueron evidentes. Hubo dos estrategias recurrentes: unos optaron por mostrarse a partir de enfatizar la valía de su propia vida: amigos, familia, logros, éxitos, momentos felices; otros optaron por mostrarse a partir de enfatizar la valía de su lugar de origen: lo grande o pequeño de su comunidad, la riqueza de su tierra, las personas que la componen, las actividades que realizan juntos, el compromiso que los une, las dificultades que enfrentan. Ambos son lugares comunes: la valía de la individualidad y el poder de la comunidad. Incluso, al solicitarles ilustraciones de su forma de hacerse visibles, los elementos iconográficos eran repetitivos, muy similares a la selección fotográfica que se hace para páginas electrónicas como Facebook o MySpace.

Según Watzlawick, Beavin y Jackson (1997), esta forma de exponerse también encuentra sentido a partir de un sistema de significación. El sistema que dio sentido a las exposiciones de Entre Voces fueron las relaciones entre los wixaritari habitantes de la sierra y los citadinos. El sistema que dio sentido a las exposiciones de los estudiantes de UNACH fue el escolar: ante los compañeros se tiene un referente idealizado; ante los docentes eso se traduce en una diversidad de necesidades.

Las autorías interculturales suponen que la visibilización basta para las buenas relaciones. Supone que esta es siempre conciente y planeada. Y lo que es más complicado aún, supone que la exposición de un sujeto es la visibilización de un grupo. Lo que da evidencia el ejercicio universitario es que la visibilización también se da en un marco discursivo y que debe aprenderse a leer desde él. 
En el proyecto Entre Voces, los docentes tenían un interés concreto: el intercambio para el mutuo reconocimiento. Por tanto, era necesario que la exposición fuera hecha de lugares comunes, pero de lugares comunes para cada quien. Así, el contraste entre uno y otro evidenciaba el contraste entre un contexto y otro. Si dicho interés no se hubiera hecho evidente, el sentido de las exposiciones hubiera resultado oscuro y vago. Por tanto, lo que da la utilidad de la visibilización no es la visibilización en sí, sino el sistema de significación que se utiliza como referente.

\section{CONCLUSIONES SOBRE LA REPRODUCCIÓN DE LA METODOLOGÍA DE AUTORÍA DE «ENTRE VOCES»}

Al fin, la experiencia de reproducción dejó claro que la simetría enunciativa de un texto no depende de procedimientos específicos, sino de su lectura a partir de evidenciar el marco de significación que lo rodea. Un texto no es más o menos simétrico, más o menos legítimo por si hace tal o cual cosa. Ayuda a la educación para la diversidad si hace evidente el sistema que opera detrás de las voces. Así, lo que parece ser una serie de procedimientos metodológicos dibujados por Entre Voces, se convierte en rubros que deben hacerse visibles para desentrañar un sentido textual mucho más profundo.

La propuesta de Entre Voces no es un camino que asegure la construcción conjunta y equilibrada del saber, sino una serie de retos que deben esclarecerse a partir de la interacción misma de los sujetos. Sin esta reflexión metacomunicativa no solo cualquier mensaje textual se hace inútil, sino que el propósito educativo se pierde.

Si se mira bien, al esclarecer el sentido metacomunicativo de un texto, de hecho, se fomenta un formato informativo, tipo de texto que propicia la relación simétrica entre emisores y receptores. No se puede hacer evidente el funcionamiento textual en un género literario o en un cuaderno de trabajo. Sólo el género informativo permite este esclarecimiento en capas de los textos. 
De esta manera, el formato no es el que garantiza que un texto educativo fomente la igualdad, sino el ejercicio metacomunicativo. Lo que hace que Entre Voces enseñe sobre una experiencia a partir de la experiencia misma es el esclarecimiento de los mecanismos de significación que operan tras el texto. Sin ello, aun cuando sean textos informativos, no promoverán del todo la igualdad.

\section{PERSPECTIVAS A FUTURO EN LA AUTORÍA INTERCULTURAL DE LIBROS EDUCATIVOS}

La verdadera preocupación de los textos educativos para la interculturalidad no debe ser, pues, el garantizar la simetría entre los sujetos participantes. Como ya expliqué, es difícil controlar la naturaleza misma de las interacciones humanas y estas pueden ser, aun cuando las condiciones sean contrarias, complementarias, pese a cualquier esfuerzo. Así, pues, lo que legitima al texto intercultural es la evidencia del sistema de significación detrás de sus relaciones.

La contribución de Entre Voces es que muestra, con su forma de construir el libro, las distintas capas de significación que desentrañan una serie de fenómenos vinculados con el diálogo intercultural. El texto enseña sobre la interacción a partir de analizar la interacción. Si no se analiza, el procedimiento resulta inútil. Las capas que interesan para el análisis, en todo caso, son las siguientes:

1. La construcción de la interacción entre autores.

2. El tipo de diálogo que establecen entre ellos.

3. Los contenidos que eligen discutir.

4. La construcción discursiva de sí mismos frente al otro.

5. La construcción discursiva del otro frente a sí mismos.

6. La construcción discursiva de su destinatario.

7. Las estrategias didácticas seleccionadas para la enseñanza de la interculturalidad. 
Por ello, posibilitando el análisis de la interacción intercultural, se fomenta un procedimiento de autoría intercultural. La apuesta, entonces, para la autoría de nuevos textos educativos interculturales debería ser hacia la creación de nuevos espacios para vivir la experiencia misma de encuentros interculturales en donde los autores puedan hacer reflexión sobre su encuentro. No se podría hablar de diálogo intercultural sin haberlo practicado y reflexionado sobre él con el otro. Y en las vicisitudes de este ejercicio, se podrán encontrar verdaderos caminos pertinentes para una sociedad que busca enfrentar las dimensiones políticas de la diversidad. La recomendación última es, pues, hacia la exploración del análisis grupal sobre la autoría grupal. Ahí se encontrarán nuevas pistas educativas. 


\section{BIBLIOGRAFÍA}

Barthes, R., 2005, El grano de la voz. Entrevistas 1962-1980, Siglo XXI, Buenos Aires.

Corona Berkin, S., 2007, Entre voces... Fragmentos de educación «entrecultural», Universidad de Guadalajara, Guadalajara.

Martínez Bonafé, J., 2002, Políticas del libro de texto escolar, Morata, Madrid.

Pérez Daniel, M. R., 2008, «El Discurso Intercultural en Tres Textos Educativos Mexicanos Contemporáneos: Análisis de las Unidades de Sentido», Tesis de doctorado en Educación, Universidad de Guadalajara, Guadalajara.

Podestá, R., 2007, Encuentro de Miradas: El territorio visto por diversos autores, CGEIB, México.

UNEM, 2007, Los hombres y las mujeres del maíz: Democracia y derecho indígena para el mundo, CIESAS, México.

Veron, E., 1999, Esto no es un libro, Gedisa, Barcelona.

Watzlawick, P., J. Beavin Bavelas, y D. Jackson, 1997, Teoría de la comunicación humana, Herder, Barcelona. 


\section{Notas}

${ }^{1}$ http://eib.sep.gob.mx/

${ }^{2}$ Proyecto de investigación financiado por la Universidad Autónoma de Chiapas, bajo la convocatoria de ex becarios 2009, titulado Libro de texto para la reflexión intercultural universitaria en el programa de tutorías: ciudadanía y mexicanidad desde la perspectiva del estudiante.

${ }^{3}$ Este ejercicio se realizó en el seno de la Universidad Autónoma de Chiapas, institución que cuenta con una patente representatividad de la diversidad cultural del estado dentro del aula, entre sus docentes y estudiantes. Si bien en su proyecto académico contemplaba asumir una perspectiva intercultural en sus acciones, hasta el año 2010 no había existido programa alguno que lo hiciera evidente. Se hablaba de ella, se asumía, se problematizaba de distinta forma, pero no se trataba con claridad. Por eso, a partir del interés de la institución de fijar una estrategia de atención, se creó un primer encuentro entre distintos estudiantes de las diferentes facultades para hablar y reflexionar sobre la diversidad que caracterizaba la Universidad.

${ }^{4}$ Los estudiantes participantes se involucraron en el proyecto voluntariamente, movidos solo por el interés de compartir su experiencia. Algunos docentes de sus facultades apoyaron en la coordinación del taller, esperando poder sistematizar la experiencia de tal manera que se pudiera crear el texto: un texto educativo que enseñara sobre el diálogo intercultural a partir del ejercicio de diálogo entre los mismos estudiantes.

${ }^{5}$ Tanto el ejercicio de Entre voces como el de esta réplica partieron de la premisa de que no hay diálogo sin conflicto. Si bien este principio intercultural se asumió en ambos ejercicios, las complicaciones para reflexionar en torno al conflicto no, por lo que ellas fueron ahora el objeto de análisis. Las conclusiones derivadas de ese análisis son las expuestas aquí.

Fecha de recepción: 30 de julio de 2010.

Fecha de aceptación: 21 de febrero de 2011. 